\title{
Successful endoscopic closure of iatrogenic duodenal perforation with the new Padlock Clip
}

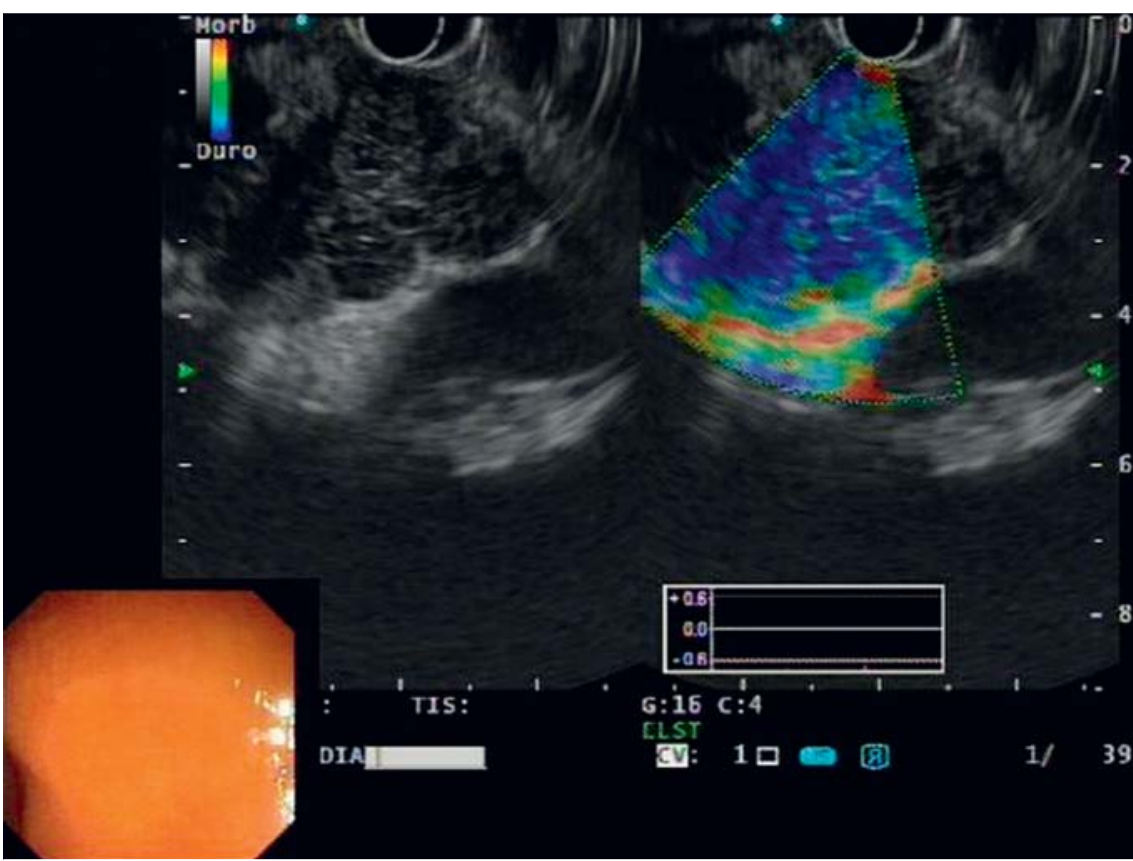

Fig. 1 Solid lesion seen in the pancreatic head on endoscopic ultrasound.

Although duodenal perforations are rare [1], they represent one of the most critical complications of endoscopic ultrasound (EUS) and may be fatal in elderly patients. Following the introduction of endoscopic clips, stents, and over-thescope systems into clinical practice, endoscopic management of perforations has became the first therapeutic option $[2,3]$.

We present the case of a 62-year-old man with jaundice, who was referred to the Digestive Endoscopy Unit of Humanitas Research Hospital (Rozzano, Italy) to undergo EUS-guided fine-needle aspiration of a solid lesion in the pancreatic head ( Fig.1). The EUS was performed using a linear echoendoscope (GF-UCT140; Olympus Optical Co., Tokyo, Japan), $\mathrm{CO}_{2}$ insufflation, and with the patient under deep sedation with propofol.

During scope withdrawal through the duodenum, we observed a type-1 [4], full-thickness defect, of $13 \mathrm{~mm}$ in diameter, at the upper duodenal knee ( $\triangleright$ Fig. 2).
A stiff guidewire was placed in the duodenum to help expose the defect. A twin grasper (Ovesco Endoscopy AG, Tübingen, Germany) was used to approximate the mucosal edges of the perforation. Then, a gastroscope loaded with the new Padlock Clip (Aponos Medical Co., King-

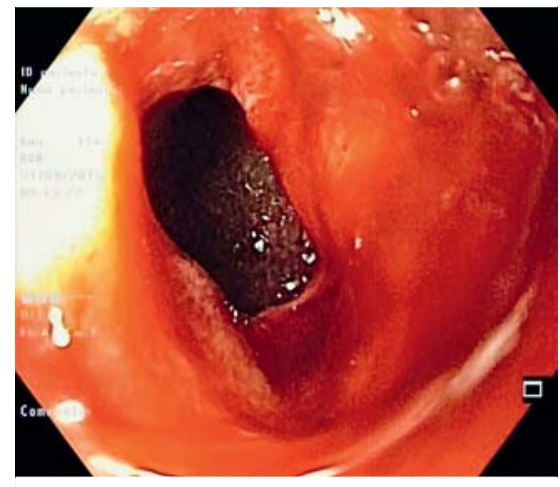

- Fig. 2 Full-thickness defect at the upper duodenal knee.

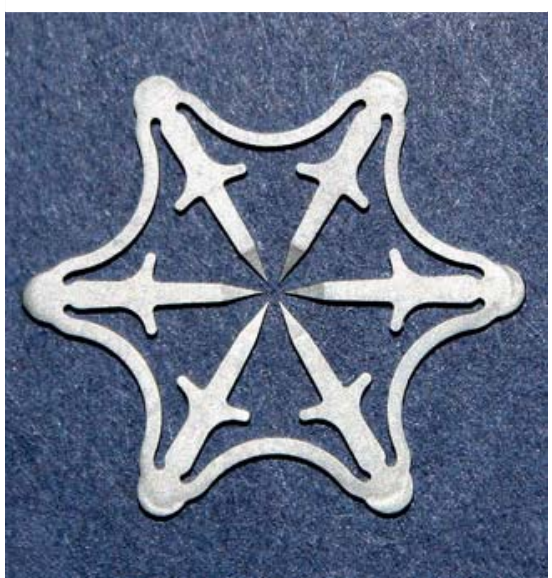

- Fig. 3 The new Padlock Clip (Aponos Medical Co., Kingston, New Hampshire, USA).

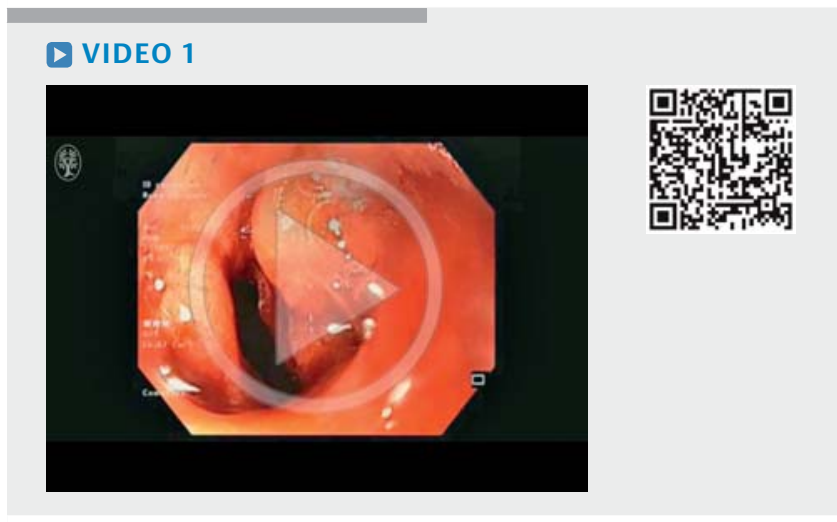

- Video 1: Endoscopic closure of an iatrogenic duodenal perforation using the new Padlock Clip system (Aponos Medical Co., Kingston, New Hampshire, USA). 


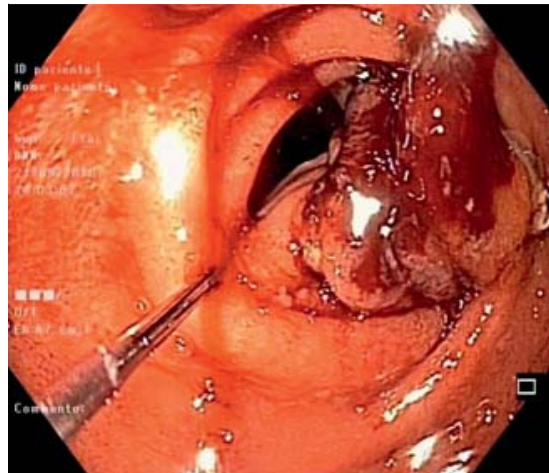

$\checkmark$ Fig. 4 Final endoscopic appearance after deployment of the Padlock Clip (Aponos Medical Co., Kingston, New Hampshire, USA).

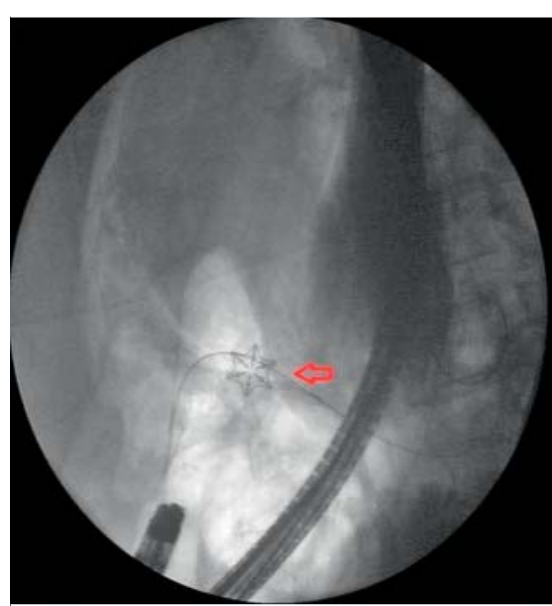

- Fig.5 Final fluoroscopic appearance of the Padlock Clip (arrow; Aponos Medical Co., Kingston, New Hampshire, USA). ston, New Hampshire, USA) ( $\mathbf{F i g . 3}$ ) was used to seal the defect ( $\triangleright$ Video 1 ). Finally, a contrast radiograph confirmed the complete closure of the perforation

\section{( Fig. 4, $>$ Fig.5).}

The Padlock Clip is a new over-the-scope system designed to be placed parallel to the endoscope, without occupying the operative working channel [5]. To our knowledge, this is the first clinical experience of closure of a duodenal iatrogenic perforation using the Padlock Clip.

$$
\text { Endoscopy_UCTN_Code_CPL_1AL_2AB }
$$

\section{Competing interests}

None

\section{The Authors}

Andrea Anderloni ${ }^{1}$, Mario Bianchetti ${ }^{2}$, Benedetto Mangiavillano², Alessandro Fugazza1, ${ }^{1,}$ Milena Di Leo', Silvia Carrara', Alessandro Repici ${ }^{1,4}$

1 Digestive Endoscopy Unit, Division of Gastroenterology, Humanitas Research Hospital, Rozzano, Italy

2 Gastrointestinal Endoscopy Unit, Humanitas Mater Domini, Castellanza, Italy

3 Digestive Endoscopy Unit, University of Parma, Parma, Italy

4 Humanitas University, Rozzano, Italy

\section{Corresponding author}

\section{Andrea Anderloni, MD, PhD}

Digestive Endoscopy Unit, Division of Gastroenterology, Humanitas Research Hospital, Via Manzoni 56, 20089 Rozzano (Milano), Italy

Fax: +39-02-82247308

andrea.anderloni@humanitas.it

\section{References}

[1] Carrara S, Arcidiacono PG, Mezzi G et al. Pancreatic endoscopic ultrasound-guided fine needle aspiration: complication rate and clinical course in a single centre. Dig Liv Dis 2010; 42: 520 - 523

[2] Paspatis GA, Dumonceau JM, Barthet M et al. Diagnosis and management of iatrogenic endoscopic perforations: position statement from the European Society of Gastrointestinal Endoscopy (ESGE). Endoscopy 2014; 46: 1-19

[3] Guarner-Argente C, Córdova H, MartínezPallí G et al. Yes, we can: reliable colonic closure with the Padlock-G clip in a survival porcine study (with video). Gastrointest Endosc 2010; 72: 841-844

[4] Mangiavillano B, Caruso A, Manta R et al. Over-the-scope clips in the treatment of gastrointestinal tract iatrogenic perforation: a multicenter retrospective study and a classification of gastrointestinal tract perforations. World J Gastrointest Surg 2016; 8: $315-320$

[5] Armellini E, Crinò SF, Orsello M et al. Novel endoscopic over-the-scope clip system. World J Gastroenterol 2015; 21: 13587 13592

\section{Bibliography}

DOI http://dx.doi.org/10.1055/s-0042-124177

Endoscopy 2017; 49: E58-E59

(c) Georg Thieme Verlag KG

Stuttgart · New York

ISSN 0013-726X 